\title{
Professional education among haemophilia nurses: a survey of current practices
}

Simon Fletcher, Steve Chaplin, Cathy Harrison, Kristian Juusola, Norma Collins

Background: Guidance from the European Association for Haemophilia and Allied Disorders (EAHAD) sets out the educational milestones haemophilia nurses should aim to achieve. However, little is known about the resources nurses use for education and current awareness. Aims: To assess the current educational level of haemophilia nurses, how and where they access ongoing education, where they feel they need extra support, and how best this teaching could be delivered. Methods: Haemophilia nurses in the Haemnet Horizons group devised and piloted a questionnaire. This was distributed in hard copy to nurses attending the 2019 EAHAD Congress and promoted as an online survey hosted by Survey Monkey. Results: Seventy-five replies were received from nurses in Europe (46 in the UK),

SIMON FLETCHER

Lead Haemophilia Research Nurse, Oxford Haemophilia

and Thrombosis Centre, Oxford University Hospitals,

Oxford, UK. Email: sfletcher26@aol.com

STEVE CHAPLIN

Haemnet, UK. Email: steve@haemnet.com

CATHY HARRISON

Advanced Nurse Practitioner, Sheffield Haemophilia and Thrombosis Centre, Sheffield Teaching Hospitals, Sheffield, UK

KRISTIAN JUUSOLA

Paediatric Haemophilia Nurse, Oulu University Hospital, Oulu, Finland

NORMA COLLINS

Clinical Nurse Specialist, Coagulation Centre, Cork

University Hospital, Wilton, Cork, Ireland

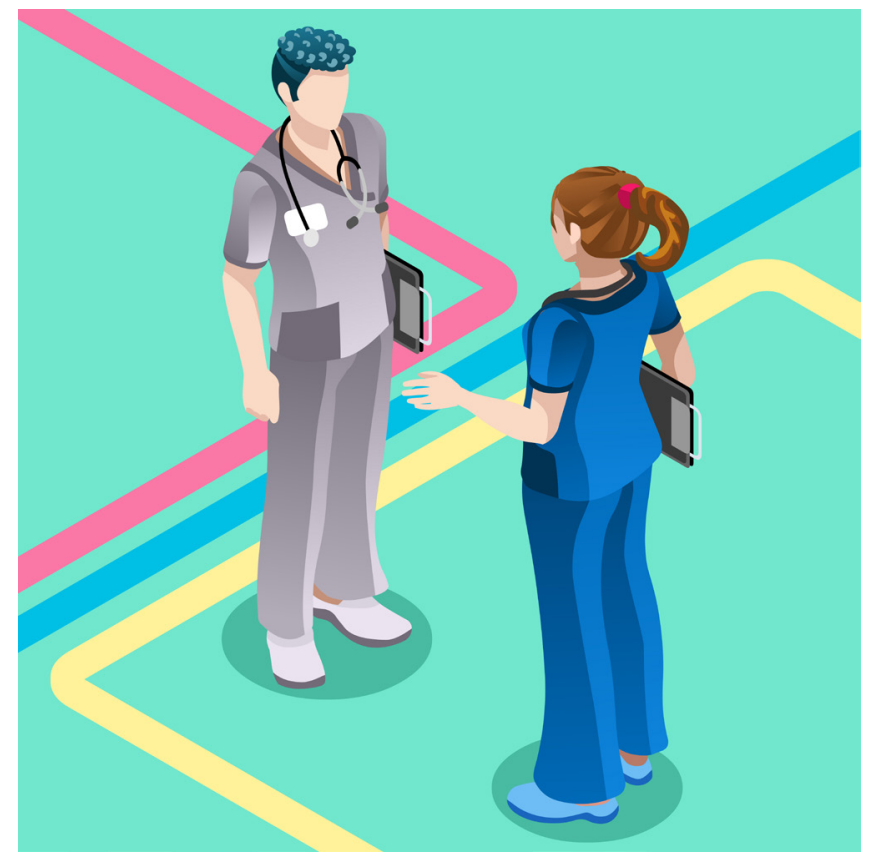

A study on how haemophilia nurses access education and their current educational needs shows the use of a wide range of educational resources, and a preference for educational activities that are face-to-face, interactive, based on patient cases, and focused on the multidisciplinary team.

and two from nurses in Chile and the Philippines. Most described their role as 'specialist nurse', with the majority having worked in haemophilia care for up to ten years. Half had a nursing degree and one quarter had a nursing diploma. Three quarters had attended at least one course specifically related to haemophilia nursing. Almost all used academic sources, study days and the websites of health profession organisations as information sources.

This is an Open Access article distributed under the terms of the Creative Commons Attribution-NonCommercial-NoDerivs License (https://creativecommons.org/licenses/by-nc-nd/3.0/) which permits use and distribution in any medium, provided the original work is properly cited, the use is non-commercial, and no modifications or adaptations are made. Copyright is retained by the authors. 
Most also used Google or Wikipedia, but fewer used Twitter. Patient association websites were more popular among non-UK nurses. About half attended sponsored professional meetings and three quarters reported that educational meetings were available in their workplace. A clear majority preferred interactive and face-to-face activities using patientfocused content. Conclusions: The study shows that nurses, predominantly in Western Europe, access a range of educational resources, most of which are 'traditional'. Use of online sources is high, but social media are less popular than Google or Wikipedia. Further research is needed to explore the potential of new media for haemophilia nurse education, and whether the current educational levels and needs highlighted in the survey remains the same across the whole of Europe.

Keywords: Professional education, continuing professional development, specialist nurses, online resources, social media, Europe

n 2016, the Nurses Committee of the European Association for Haemophilia and Allied Disorders (EAHAD) proposed a curriculum for use as "a resource to outline education for the haemophilia nurse and contribute to the standardisation and benchmarking of haemophilia nursing care and thus to improvement in the quality of patient care" [1]. Its recommendations were based on a 2012 online survey of 94 haemophilia nurses in Europe, covering their educational activities and attainment, work activity, and future professional development ${ }^{[2]}$.

The 2012 survey was a broad scoping exercise that specifically assessed the role of haemophilia nurses rather than their educational needs and achievements (though it did find that nurses used a variety of ways to learn). The information drawn from the survey was used to inform the content of EAHAD's European Curriculum for Nurses Working in Haemophilia, which has since provided a useful framework for what nurses should be striving to achieve. However, there has been little research to establish the extent to which nurses have approached this target.

The study reported here was designed to assess the current educational level of haemophilia nurses, how and where they access ongoing education, where they feel they need extra support, and how best this teaching could be delivered. It was initiated at the third meeting of the Haemnet Horizons group, held in London, UK, in 2018. Haemnet Horizons is a trans-
European working group supported by Haemnet (www. haemnet.com) that fosters and develops research by haemophilia nurses. A subgroup was established specifically to work on the study.

\section{METHODS}

A group of 19 haemophilia nurses from Croatia, Denmark, Finland, France, Germany, Ireland the Netherlands, Norway, Spain and the UK participated in the Horizons subgroup. The subgroup drafted a questionnaire devised by consensus, based on personal professional experience and expertise.

The draft questionnaire was piloted with 19 members of the full Horizons working group and their colleagues. Pilot responses showed that, in a group of relatively highly educated and motivated nurses, no single method of education was dominant, and that the time required for education and the cost of accessing it presented challenges for all respondents.

Following the pilot, a number of changes were made to how questions were phrased to make it easier for those whose first language is not English to understand. The revised questionnaire comprised 16 questions covering the respondents' current role and educational choices (e.g. providers used, frequency), perceived needs and satisfaction. This was distributed in hard copy to nurses attending the 2019 EAHAD Congress in Prague, Czech Republic, and promoted as an online survey hosted by Survey Monkey. Respondents could return the completed hard copy questionnaire at the Congress or via mail; hard copy returns and online returns were reviewed to exclude duplicates.

\section{RESULTS}

Seventy-five questionnaires were returned. Four respondents did not state their country of practice; of the remainder, two were from outside Europe (Chile and the Philippines). Of the known European respondents, 46 (66\%) were from the UK, four each were from Finland, Ireland and Spain, three each were from Denmark and the Netherlands, two were from Sweden, and one from each of Belgium, Croatia and Portugal.

Role, experience and educational attainment Forty-eight (64\%) respondents described their role as specialist nurse, nine said they were a research nurse $(12 \%)$, six were staff nurses $(8.0 \%)$, and six $(8.0 \%)$ said they were advanced nurse practitioners. The 11 remaining respondents described their role as clinical academic (2), Band 5 nurse (1) and haemophilia 
Figure 1. Duration working in haemophilia care ( $n=74$ responses) and in current post ( $n=75$ respondents) (\% respondents, years)

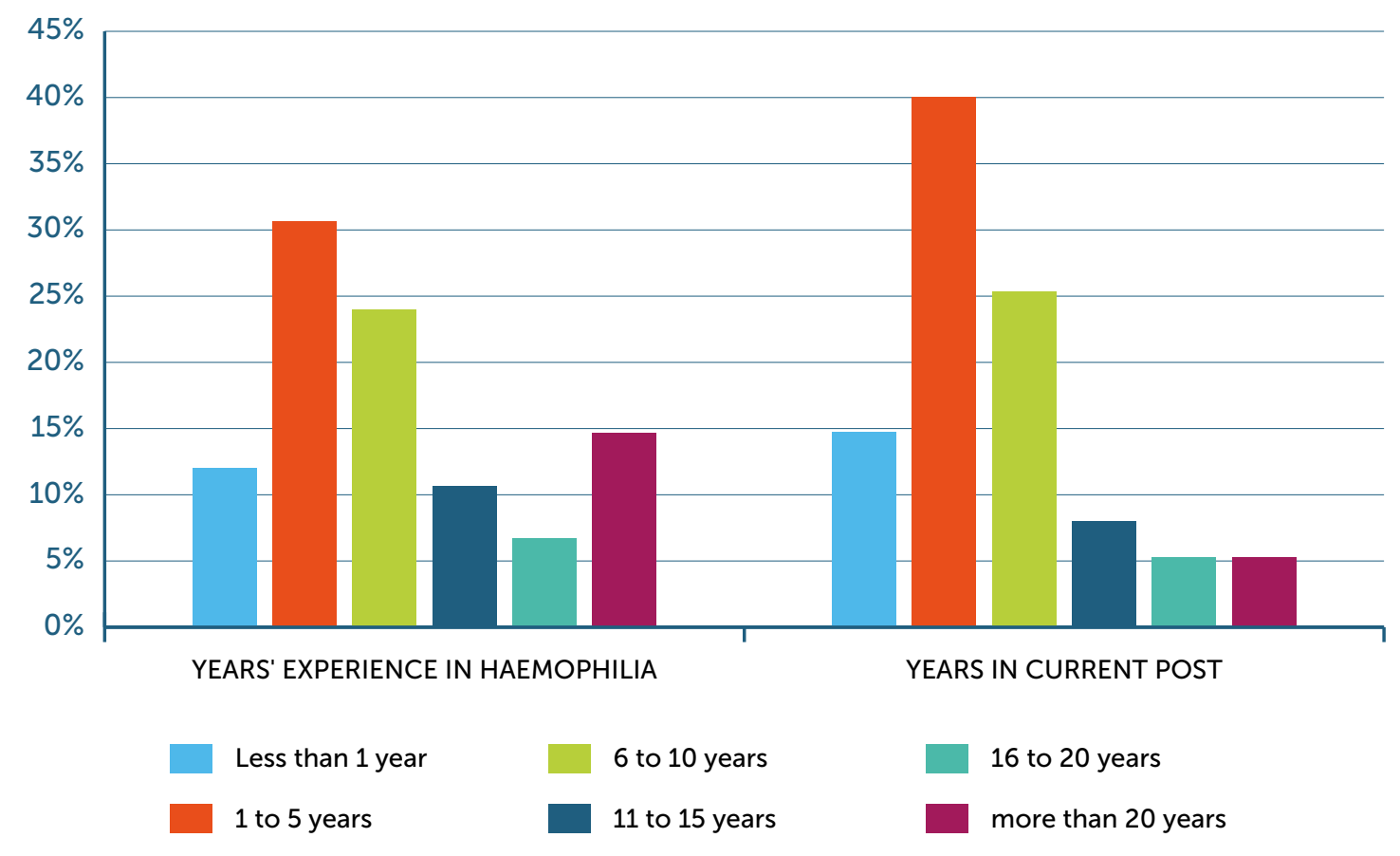

Table 1. Haemophilia-specific courses attended by respondents ( $n=58 / 74$ responses)

\begin{tabular}{|c|c|c|}
\hline COURSE & $\mathbf{N}$ & $\% *$ \\
\hline Introduction to Haemophilia (UK) & 15 & 20 \\
\hline Essentials of Haemophilia (UK) & 25 & 33 \\
\hline Advancing Haemophilia Nursing (UK) & 15 & 20 \\
\hline Contemporary Care of Bleeding Disorders (UK) & 15 & 20 \\
\hline Atención Integral de Enfermería en el Paciente con Hemofilia (Spain) & 4 & 5.3 \\
\hline Pharma-sponsored haemophilia meetings & 22 & 29.3 \\
\hline Dutch Haemophilia Nurses Association study days & 2 & 2.7 \\
\hline Other national training course & 9 & 12 \\
\hline
\end{tabular}

* Percentages are as a proportion of total group $(n=75)$; individuals may have attended more than one course

nurse (1); two did not answer. Almost two thirds of respondents had been working in haemophilia care for up to ten years (one respondent did not provide information), and $80 \%$ had been in their current post for up to ten years (Figure 1 ).

A nursing degree was the most frequent level of academic attainment among respondents (47\%), followed by a diploma (25\%) and a nursing qualification $(16 \%)$. Nine respondents (12\%) held a postgraduate qualification; these included one postgraduate diploma, six master's degrees and two doctorates.

Seventy-seven percent of respondents stated they had attended at least one educational course specifically related to haemophilia nursing (Table 1).

\section{Current educational activity}

Respondents were asked to indicate which educational resources they currently used to maintain current awareness of clinical issues (Figure 2). Academic sources were the most frequently used, with journals or textbooks used at least sometimes by $82-95 \%$ of respondents. Study days and the websites of professional organisations were used at least sometimes by $91-93 \%$ of respondents. Google and/or Wikipedia were used at least sometimes by $88 \%$ of respondents. About half of respondents used patient association websites (57\%), the professional networking site Linkedln (44\%), and the online education site Medscape $(45 \%)$ at least sometimes. However, the sources 
most frequently used often were study days (43\%), and the online non-professional resources Google and/or Wikipedia (38\%). The sources most frequently never used were pharmaceutical company sites (76\%) and networking/microblogging service Twitter (70\%).
Respondents were asked about attendance at professional meetings, either open events organised by professional organisations or healthcare companies, or locally at their treatment centre (Figure 3). At least half of respondents attended most meetings at least

Figure 2. Current use of educational sources (\% respondents, $n=75$ )*

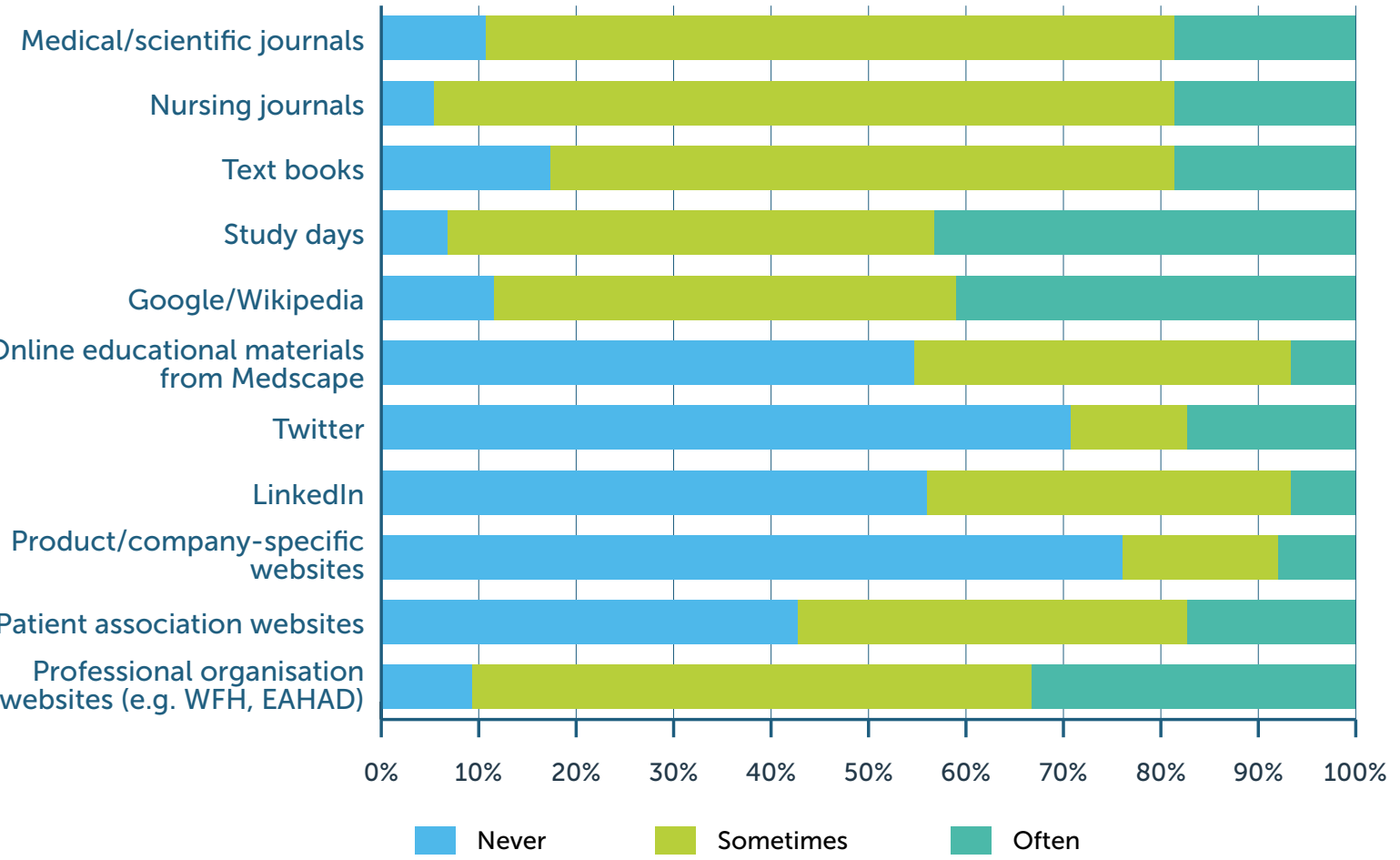

* 'Never' response includes question not answered

Figure 3. Attendance at professional meetings (\% respondents, $n=75$ )

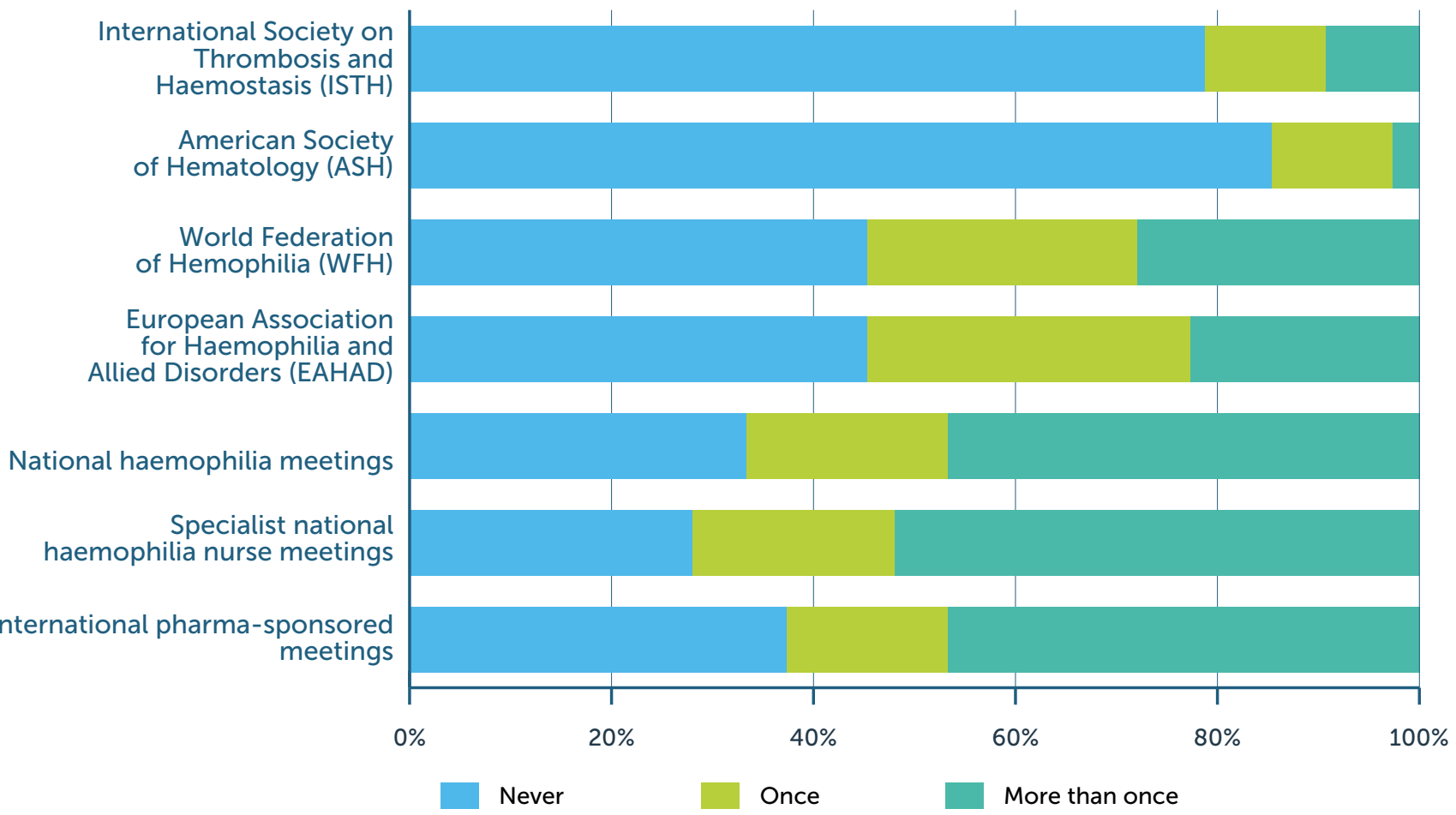




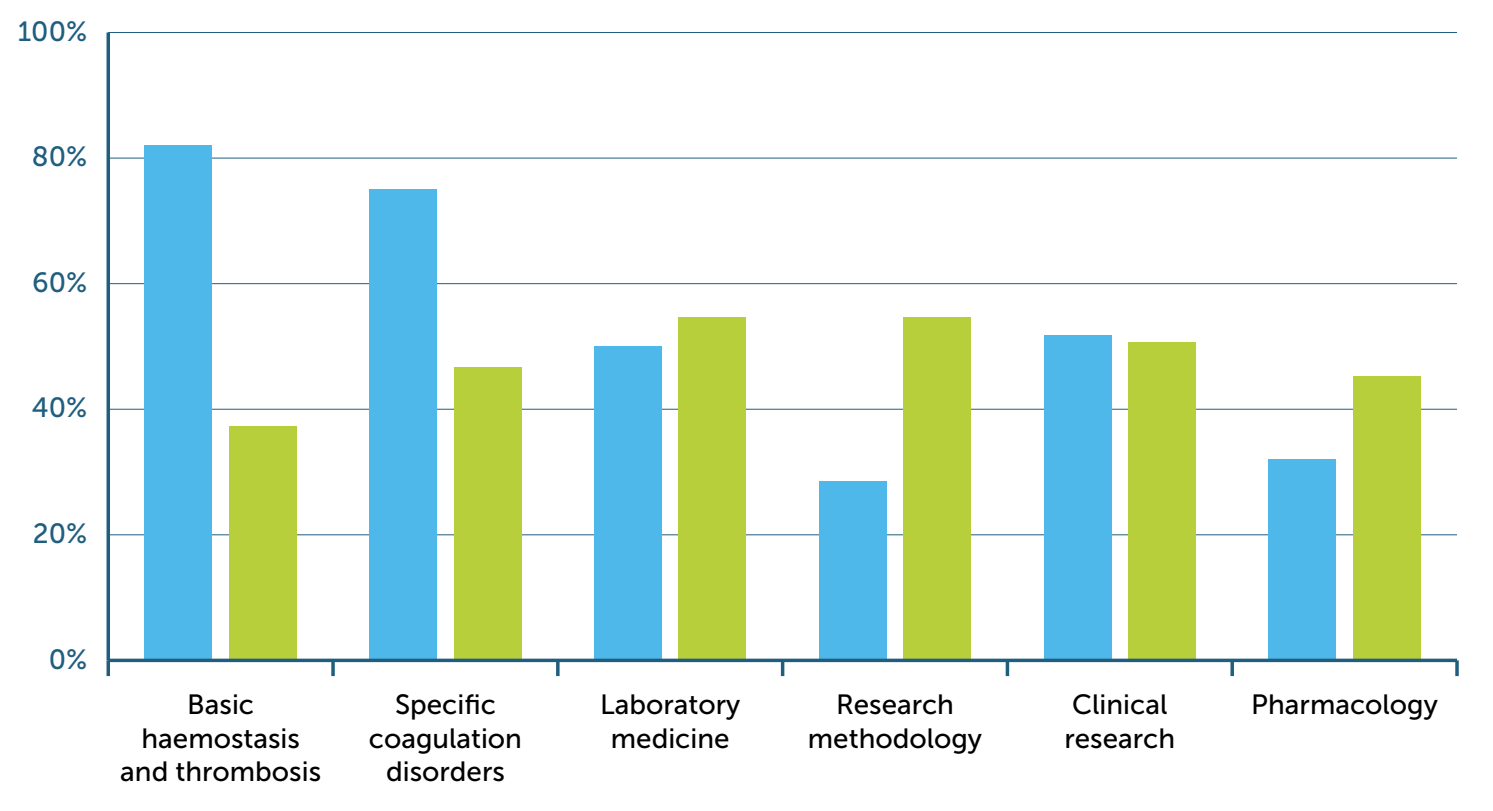

Topic covered

Self-learning need

once, the exceptions being the American Society of Hematology Annual Meeting and the International Society on Thrombosis and Haemostasis Congress. The meetings attended more than once by most respondents were meetings for specialist haemophilia nurses (53\%), international meetings sponsored by pharmaceutical companies (47\%), and national haemophilia society meetings (47\%).

Fifty-seven respondents (76\%) stated that regular educational meetings were held in the treatment centre in which they work (Figure 4). These were more often concerned with medical science rather than clinical practice or research methodology. Although respondents were not asked to link meeting content with their educational aspirations, there is no overall correspondence between the pattern of topics covered and what respondents stated they needed to learn about, except for clinical research and laboratory medicine specifically.

Of those who attended regular educational meetings in their treatment centres, most stated that the meetings were attended by nurses (84\%) and doctors (88\%), with fewer having joint meetings with physiotherapists (36\%) or laboratory staff (50\%), and $14-16 \%$ reporting meetings attended by a social worker or psychologist. Others attending meetings included students, patients, clerical staff, occupational therapists and pharmaceutical representatives. Forty-eight nurses $(84 \%)$ stated that nurses made presentations at their local meetings and 30 (62\%) had done so personally.

\section{Preferences for education provision}

Respondents were asked to score their agreement with statements about education provision on a fivepoint Likert scale, where 1 was 'strongly disagree' and 5 was 'strongly agree' (Figure 5). Just under half (45\%) stated that they were happy with their current education provision. A clear majority preferred (i.e. agreed or strongly agreed) interactive and faceto-face activities (77\% and $83 \%$ respectively) using patient-focused content (73\%). Seventy per cent agreed or strongly agreed that the content should be suitable for the multidisciplinary team, while $73 \%$ indicated that content would be used by in their local meetings. Internet-based activity, such as a webinars, would appeal to a smaller majority of respondents (60\%). Opinion was divided on whether education for nurses should be provided by nurses: $42 \%$ agreed or strongly agreed with this statement, but $19 \%$ felt the opposite and 39\% expressed no preference. Just over half (56\%) favoured accreditation of educational activities by universities.

\section{DISCUSSION}

It is clear from the survey results that haemophilia nurses use a wide variety of sources for their continuing education needs, and that most prefer interactive and face-to-face methods of delivery, and patient-focused content. Despite this, fewer than half of respondents stated that they are happy with the way they keep themselves up to date. The results reflect the practice 


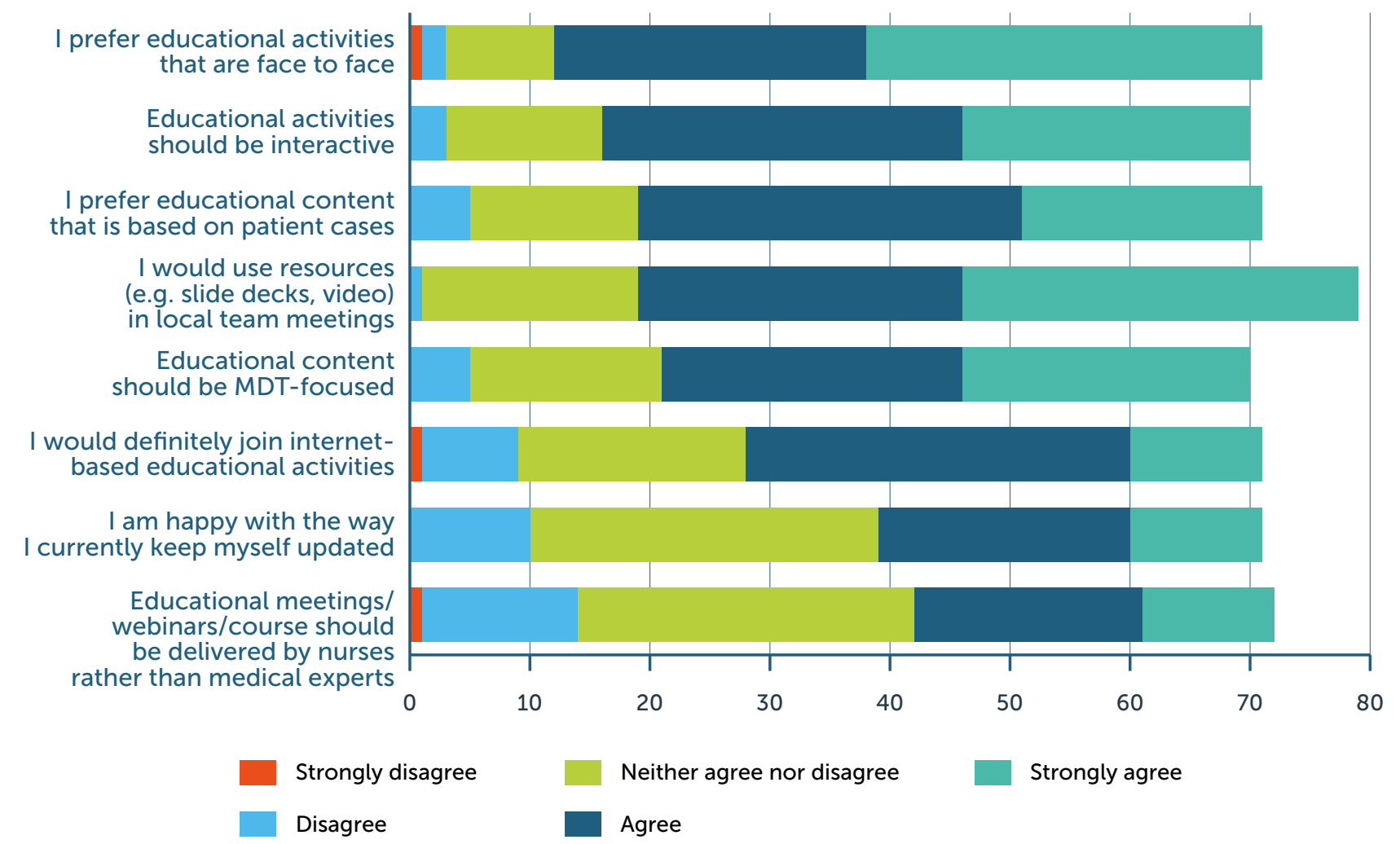

of experienced nurses, most of whom are established in their current post. However, the respondents were predominantly from Western European countries, and over half from the UK, with little representation from other parts of Europe.

Almost half of respondents described their role as specialist nurse; a further five were advanced nurse practitioners and one was a haemophilia nurse. This suggests, after allowing for variable interpretation of job titles, that at least two thirds of respondents were engaged in the delivery of specialised haemophilia care. Courses hosted in the UK (including online access) account for the largest proportion of haemophiliaspecific training; Haemnet courses are available globally and are used by nurses resident outside the UK.

Traditional formats such as journals, textbooks, study days and 'classroom-based' courses were the most popular methods of keeping up to date. The online education site Medscape was used by fewer than half of respondents. By contrast, the ready availability of Google and Wikipedia probably explains their popularity. Non-UK respondents reported greater use of patient association websites and product-specific or pharmaceutical company websites than UK nurses. The survey did not explore the reasons for this difference, but possible factors include access to information in the domestic language and local regulations governing information provision and practice.

Use of Twitter and other social media formats was unexpectedly low, and at this time it is unclear why. It has been suggested that any reticence to use or engage with social media may be a consequence of concerns about breaches of patient privacy, possible violations of patient and professional boundaries, and the attendant damage to professional image ${ }^{[3]}$. In the UK, the situation may be compounded by the vague and contradictory nature of national and local guidance on the use of social media ${ }^{[4]}$ The reason for the reticence of nurses from other European countries to use these sites is currently not known, and further research is required in this area.

There is growing evidence that the way society obtains medical information has changed as the internet has become increasingly accessible, and social media has become more pervasive ${ }^{[5-7]}$. Whereas individuals once relied on medical experts to meet their needs, obtaining information now seems to be a more active process, and one in which the expert is no longer perceived to be the only authority ${ }^{[8]}$. Access to medical information is now easier than ever: the US Health Information National Trends Survey showed that, in 2017, $79 \%$ of respondents had used the internet to find medical or health information for themselves ${ }^{[9]}$. It is possible 
that the nurses sampled here are not fully aware of the potential of social media for current awareness and to keep in touch with the needs of their patients. Further research is needed to clarify the potential contribution of these media in haemophilia care.

Local educational meetings are taking place regularly in some areas and nurses are able to access them, though a third of respondents stated that they did not make presentations at these meetings. Further research is required to determine the reasons for this, which may include not being invited to present or reluctance to volunteer. Pressure on time and resources may be another factor. Some educational meetings are subsidised by the pharmaceutical industry and nurses may be offered financial support to attend; similar assistance may be available for prestigious international conferences While this is a valued option to meet the relatively high costs of registration, travel and accommodation, there is a risk that such invitations may not be equally available to everyone.

This survey focused on accessing resources for education rather than continuing professional development (CPD). There is, of course, wide overlap, but CPD encompasses aspects of clinical practice (e.g. competencies) and professional regulation that go beyond learning and the acquisition of knowledge. Accessing education is, to a greater extent, affected by the personal choices and resources available, and therefore reflects nurses' preferences and opportunities.

\section{CONCLUSION}

In summary, this study indicates that haemophilia nurses are actively engaged in continuing education via a wide range of sources; however, a proportion are dissatisfied with current provision. Traditional sources of education are widely used, and use of online educational sources is high. However, uptake of social media is relatively low and less popular than Google or Wikipedia. Further research is needed to explore the potential of new media for haemophilia nurse education.

It should be noted that there is a significant Western European bias to this study, which has appeared despite every attempt being made to reach a wider number of countries, including launching the questionnaire in the Czech Republic at the EAHAD Congress. This remains a limitation of the study and further research is therefore needed to explore whether the current educational levels and needs highlighted in the survey remains the same across the whole of Europe.

\section{ACKNOWLEDGMENTS}

Sobi and CSL Behring provided grants to cover the costs of the Horizons meetings.

The authors would also like to thank Michael Holland, Kate Khair and Sandra Dodgson (Haemnet) for facilitating the Horizons meetings from which this paper emerges.

The authors have advised no interests that might be perceived as posing a conflict or bias.

This article reports on a survey of healthcare professionals and did not require research board approval.

\section{ORCID}

Simon Fletcher (iD https://orcid.org/0000-0001-9018-6176 Cathy Harrison (iD https://orcid.org/0000-0002-9336-5249

\section{REFERENCES}

1. EAHAD Nurses Committee; Harrington C, Bedford M, Andritschke $K$, et al. A European curriculum for nurses working in haemophilia. Haemophilia 2016; 22: 103-9. doi: 10.1111/ hae. 12785

2. Schrijvers $L$, Bedford $M$, Elfvinge $P$, et al. The role of the European haemophilia nurse. J Haem Pract 2014; 1: 24-7. doi: 10.17225/jhp.00008

3. Ventola CL. Social media and health care professionals: benefits, risks, and best practices Pharmacy $\&$ Therapeutics. 2014: 39 (7): 491-520.

4. Nursing and Midwifery Council. Guidance on using social media responsibly. Last updated 3 January 2019. Available from https://www.nmc.org.uk/globalassets/sitedocuments/ nmc-publications/social-media-guidance.pdf (accessed 1 November 2019).

5. Murthy D. Twitter and health. In: Twitter: Social Communication in the Digital Age, 2nd edn. Cambridge: Polity Press; 2018.

6. Jiang S, Beaudoin CE. Health literacy and the internet: an exploratory study on the 2013 HINTS survey. Computers in Human Behavior 2016; 58: 240-8. doi: 10.1016/j. chb.2016.01.007.

7. Orsini M. Social media: how home health care agencies can join the chorus of empowered voices. Home Health Care Management \& Practice. 2009; 22: 213-7. doi:10.1177/1084822309343871.

8. Nichols T. The Death of Expertise: The Campaign Against Established Knowledge and Why it Matters. Oxford: Oxford University Press; 2017

9. National Cancer Institute. Health information national trends survey (HINTS). 2014. Available from https://hints.cancer.gov (Accessed 15 November 2019)

HOW TO CITE THIS ARTICLE:

Fletcher S, Chaplin S, Harrison C, Juusola K, Collins N.

Professional education among haemophilia nurses: a survey of current practices. J Haem Pract 2020; 7(1): 1-7. https://doi.org/10.17225/jhp00150. 